\title{
Effects of antihistamines in adult asthma: a meta-analysis of clinical trials
}

\author{
E. Van Ganse*, L. Kaufman**, M.P. Derde**, \\ J.C. Yernault + , L. Delaunois ${ }^{++}$, W. Vincken*
}

Effects of antihistamines in adult asthma: a meta-analysis of clinical trials. E. Van Ganse, L. Kaufman, M.P. Derde, J.C. Yernault, L. Delaunois, W. Vincken. (OERS Journals Ltd 1997.

ABSTRACT: A meta-analysis of clinical trials of antihistamines was performed to assess the risk-benefit ratio of this therapeutic class in asthma.

Double-blind randomized placebo-controlled trials assessing lung function changes under repeated use of antihistamine in adult asthma were selected, and the quality of studies was scored. Morning peak expiratory flow rate (PEFR) was the primary outcome: an effect size was computed for each study, with a $95 \%$ confidence interval $(95 \% \mathrm{CI})$, and a mean effect size was computed, combining all studies. Effect sizes were also determined for secondary outcomes: evening PEFR, forced expiratory volume in one second (FEV1) and daily use of inhaled $\beta$-agonists.

Nineteen studies were included in the meta-analysis. Mean quality score of studies was $\mathbf{5 9 . 4 \%}$; asthma was generally uncontrolled at study inclusion. Altogether, 582 antihistamine-treated and 557 placebo-treated asthma patients were evaluable. Antihistamines had little effect on airway calibre (mean increase in morning PEFR: $13 \mathrm{~L} \cdot \mathrm{min}^{-1}$; $95 \mathrm{CI}$ : 8-18 L·min'-1) and on use of inhaled $\beta$-agonists (mean reduction in daily use: 0.4 doses; $95 \%$ CI: $0-0.8$ doses). Sedation occurred more often with antihistamines than with placebo $(\mathbf{p}<0.001)$; additional side-effects were mentioned, including weight gain, altered taste, headache and dry mouth.

Respiratory and systemic effects observed after repeated use of antihistamines do not support the use of these medications in the treatment of asthma; better designed studies could affect this appraisal.

Eur Respir J 1997; 10: 2216-2224.
*Respiratory Division, Academic Hospital University of Brussels (AZ VUB), Brussels. **Dept of Biostatistics, University of Brussels (AZ VUB), Brussels. +Dept of Pneumology, University of Brussels (ULB Erasme), Brussels. ${ }^{++}$Dept of Pneumology, University of Louvain (UCL Mont-Godinne), Belgium.

Correspondence: E. Van Ganse, Dept of Clinical Pharmacology, University ClaudeBernard, 162, avenue Lacassagne, BP 3041, F-69394 Lyon Cedex 03, France.

Keywords: Asthma drug therapy histamine $\mathrm{H}_{1}$-receptor blockers meta-analysis risk-benefit ratio

Received: December 31996 Accepted after revision June 281997

This study was supported by the Dept of Pneumology and the Dept of Biostatistics of the Brussels University Hospital (AZ VUB) and, in part, by the EC BIOMED grant No. BMH4 CT965033. Parts of the results have been presented at the XVth Congress of the European Academy of Allergology and Clinical Immunology (Paris, May 1992).
Asthma is a common disease, affecting up to 5\% of the population in Western countries. Management of asthma should start with patient education, information on risk factors and preventive measures. The next stage includes administration of medicines, and a stepwise approach is recommended in recent guidelines [1].

Pharmacological treatment of asthma includes two categories of drugs: bronchodilators and anti-inflammatory medications. Anti-inflammatory drugs target the inflammatory process that develops in asthmatic bronchi. This therapeutic class is represented by corticosteroids, administered via local or systemic route. Corticosteroids have demonstrated their efficacy in asthma, reducing severity and decreasing the need for symptomatic medications. Present recommendations favour early use of inhaled corticosteroids, since beneficial effects may be expected against lung function losses and disease deterioration [2].

Widespread use of corticosteroids is, however, still advised with some caution, since side-effects may occur, with both oral and inhaled formulations, as a consequence of low specificity of action. This has stimulated considerable efforts to produce anti-inflammatory agents with improved risk-benefit ratios. Research has focused on inhaled and oral agents that might inhibit the effects of pro-inflammatory mediators [3].

Disodium cromoglycate, a nonsteroidal inhaled agent, was produced as an alternative to corticosteroids. Despite encouraging results from early studies, more recent data tend to question its effects in asthma [2]. The first oral nonsteroidal compound that has been developed for the treatment of inflammation in asthma is ketotifen, an antihistamine [4]. Ketotifen was tested in asthma following initial reports of mast cell stabilizing effects and is now widely used in some countries [5]. Histamine exhibits numerous actions of relevance to asthma, such as bronchoconstriction, enhanced mucus secretion and increased vascular permeability: these actions are partly $\mathrm{H}_{1}$-receptor mediated [6]. New antihistamines are considered to be less sedating than older compounds, leading to the use of higher doses [7]. This property, combined with early reports that new antihistamines may have specific anti-allergic properties in addition to $\mathrm{H}_{1}$-blocking activity, has led to development in asthma therapy [8-10]. To date, clinical trials have delivered contradictory results, and the matter is still the subject of debate $[11,12]$. 
Meta-analysis is the statistical analysis of a large collection of results from individual studies for the purpose of integrating independent research results, and the methods are clearly defined [13-15]. Meta-analyses have been performed in several fields, including pneumology, and have contributed to providing a basis for rational interventions [16]. This study was performed to investigate the positive and negative effects of antihistamines as a therapeutic class in asthma, by retrieving and combining all relevant studies published since 1980.

\section{Materials and methods}

\section{Literature review}

Studies published between 1980 and 1990. A computerized search was performed in the Medline, Ringdoc and Emdrugs databases, looking for articles published in English between 1980 and 1990 that investigated the effects on humans of oral antihistamines in asthma. Bibliographies of retrieved articles were reviewed to identify additional articles not listed in the computerized search. This was completed by a manual search of Index Medicus and in major pneumology and allergy journals. This part of the study was completed in September 1991.

The following criteria were applied for including articles: randomized placebo-controlled trials; studies published between January 1980 and December 1990; studies with more than $50 \%$ of the patients older than $15 \mathrm{yrs}$; results published in English; evidence of peer-review process; and patients treated for more than 2 weeks. Studies which were excluded at this stage (primary exclusion) contained only pharmacodynamic and/or pharmacokinetic data; were published only as abstracts; or lacked quantified assessment of lung function (in tables or figures).

All asthma definitions given by the authors were accepted. Degrees of asthma severity or concomitant therapy were not used as criteria to reject a study, but we attempted to group the studies according to disease severity. Therefore, priority was given to authors' assessments. When such assessments were not available, we assessed severity from therapy, symptoms and lung function.

A blinded copy of the "Materials and methods" section of the studies was submitted to two pneumologists from teaching hospitals. Studies with inadequate description of patient selection or treatment regimens were excluded (secondary exclusion). Remaining studies were submitted to a quality assessment according to predefined criteria for the "Materials and methods" sections, statistical analysis and results presentation, and a global score was defined on a scale from 0-100. Quality criteria and scoring were adapted from CHALMERs et al. [17].

Studies published since 1991. The purpose of the second part of the study was to complete the meta-analysis performed in the first part, by including all additional publications published since January 1991 that were relevant to the present study. A computerized search was performed in the Medline and Embase databases, looking for articles published since January 1991 and corresponding to the criteria defined in the first part of the study. This was completed by a manual search in Index Medicus and in major pneumology and allergology journals. The articles retrieved were also submitted to a quality assessment, but there were no secondary exclusions of articles by the assessors.

Data abstraction and choice of primary and secondary outcomes. The following data were abstracted from each eligible report, using a standard data extraction form: morning and evening peak expiratory flow rate (PEFR); forced expiratory volume in one second (FEV1) values; daily use of inhaled $\beta$-agonists; incidence of sedation, fatigue and drowsiness; and incidence of other adverse events. Morning PEFR was chosen as a primary outcome; evening PEFR, FEV1 and daily use of inhaled bronchodilators were used as secondary outcomes.

In some studies, in addition to placebo, antihistamines were also compared to other asthma medications: data from this latter group were not used. When data were not tabulated, they were extracted from figures, where possible. When data were available for different treatment durations, we used the data corresponding to the longest duration of exposure. When different doses of an antihistamine were studied, we included only the data corresponding to the most effective dose, according to the authors' claim, when available. In studies where results were separated into distinct groups, (e.g. co-therapy with inhaled corticosteroids: yes/no), we recomputed the data to the whole study group using the following computation:

$$
<\mathrm{x}_{\mathrm{s}}>=\mathrm{n}_{1} \cdot \mathrm{x}_{1}+\mathrm{n}_{2} \cdot \mathrm{x}_{2} / \mathrm{n}_{1}+\mathrm{n}_{2}
$$

where $\mathrm{n}_{1}$ the number of patients in group $1, \mathrm{n}_{2}$ the number of patients in group $2,<x_{s}>$ is the mean global score in the study, $\mathrm{x}_{1}$ the mean global score in group 1 and $\mathrm{x}_{2}$ the mean global score in group 2 .

Data presentation. Tables were prepared with demographic data and selected outcomes.

Data analysis. Continuous variables (morning and evening PEFR, FEV1, daily use of inhaled bronchodilators) and effect size were computed for each study. Effect size is defined here as the mean value measured in the antihistamine group under treatment less the mean value measured in the placebo group under treatment, divided by the standard deviation (SD) of the mean value measured in the placebo group under treatment. When the value of SD was not defined, we used a weighted mean coefficient of variation, computed from the studies published during 1980-1990 where SD values were available. For each effect size, a $95 \%$ confidence interval $(95 \% \mathrm{CI})$ was computed. A mean effect size was computed as the mean of effect sizes of individual studies, and a $95 \%$ CI was computed for the mean effect size. Effect sizes and their $95 \%$ CIs were displayed on 
figures, with each effect size plotted as a proportion of the SD of the variable.

To facilitate interpretation of data, mean effects sizes have been converted into absolute numbers, $\mathrm{L} \cdot \mathrm{min}^{-1}$ for PEFR and daily doses for inhaled $\beta$-agonists. Therefore, we used a pooled SD obtained from studies where SD was mentioned.

For two outcomes, morning PEFR and daily use of inhaled bronchodilators, the homogeneity of studies was tested with a Cochran Q test [13].

Sensitivity analyses were conducted on the following subgroups of studies, to test the robustness of the results: trials investigating mild, mild-to-moderate and moderate-to-severe asthma, respectively, trials with a quality score reaching $70 \%$; trials performed with ketotifen and "new" antihistamines (excluding ketotifen); all trials that excluded co-therapy with inhaled/oral corticosteroids; and all trials, with the exception of steroid-sparing studies.

For the discrete variables, namely sedation, a MantelHaenszel test was performed to test for the presence of a difference between antihistamines and placebo for that side-effect and to test the homogeneity of studies [18].

\section{Results}

Of the studies published during 1980-1990, 64 were identified through computerized and manual searches. Based on inclusion and exclusion criteria, there were 47 primary exclusions, and 17 articles were submitted to experts for possible inclusion in analysis. There were five secondary exclusions by experts, and 12 studies were included in the analysis. Table 1 summarizes the reasons for excluding studies from final analysis (primary and secondary exclusions). A list of rejected studies is available on request.

Seven more studies were identified amongst those published since 1991 [19-25]. Information on major study characteristics of the 19 studies retrieved for our meta-analysis is presented in table 2. All degrees of

Table 1. - List of studies excluded and reason for exclusion: studies performed during 1980-1990

Reason for exclusion

Studies excluded $\mathrm{n}$

Primary exclusion

No placebo group

No peer review process

Respiratory data not quantified

Pharmacodynamic data only

No significant $\mathrm{H}_{1}$-receptor blocking activity

Abstract only

Majority of subjects aged $<15$ yrs

No oral therapy

Does not describe a clinical trial

Total number of primary exclusions

Secondary exclusion

Inadequate description of patient selection

Inadequate description of treatment regimens

Total number of secondary exclusions

Final number of studies excluded from analysis asthma severity were present, from pollen-induced asthma $[21,31,36]$ to steroid-sparing studies (oral corticosteroids [27]; inhaled corticosteroids [23]). Asthma was usually defined by a history of reversible airflow obstruction, with impaired lung function that improved considerably after use of inhaled bronchodilators. Study durations ranged 2-28 weeks.

Quality scores, selected outcomes, and authors' conclusions regarding the effects of studied antihistamines in asthma are shown in table 3. Quality assessment delivered a total score ranging $42-76 \%$ and a mean score of 59\%. Significant flaws were identified in all sections of quality scoring. Concerning study designs, deficiencies were identified in the description of treatment regimens, the prior estimate of patient numbers and data on withdrawals. In the statistical section, common weaknesses included the choice of the statistical analysis and the handling of withdrawals. Data presentation was characterized by frequent absence of study dates or tabulated data.

The effect sizes for morning PEFR are shown in figure 1 , for the 15 studies where results were available for the major outcome, together with the mean effect size for that outcome. A positive effect size shows a superiority of antihistamines over placebo. Except for two studies, all trials included the null value in the $95 \% \mathrm{CI}$ of their effect size. The mean effect size for morning PEFR was 0.13 , with a $95 \%$ CI of $0.08-0.18$. The studies were homogeneous for the measurements of morning PEFR $(\mathrm{Q}=9.82 ; \mathrm{p}=0.78)$. Computed pooled SD for morning PEFR was $104 \mathrm{~L} \cdot \mathrm{min}^{-1}$. The mean effect size thus corresponds to a bronchodilation of $13 \mathrm{~L} \cdot \mathrm{min}^{-1}$ with antihistamines, with a $95 \%$ CI of 8-18 L.min ${ }^{-1}$.

Figure 2 shows the mean effect sizes for all studied variables. The mean effect size for evening PEFR was 0.12 , with a $95 \%$ CI of $0.08-0.16$. The mean effect size for FEV1 was 0.03 , with a $95 \%$ CI of $-0.01-0.07$. From the 12 studies assessing the use of rescue inhalers, the mean effect size for daily use of inhaled bronchodilators was 0.13 , with a $95 \%$ CI of $0.01-0.25$; the studies were also homogeneous for this variable $(\mathrm{Q}=5.49$; $\mathrm{p}=$ 0.91). Computed pooled SD for daily use of inhaled bronchodilators was 3.1 doses. Thus, the mean effect size corresponds to a reduction in daily use of 0.4 doses under antihistamines, with a $95 \%$ CI of $0-0.8$ doses.

Figure 3 shows the result of sensitivity testing performed on the major outcome, morning PEFR. All effect sizes computed on subgroups of studies included the null value in their $95 \% \mathrm{CI}$, except for studies performed with new antihistamines. The highest effect size for antihistamines was obtained with studies in mildto-moderate asthma

The incidence of sedation was mentioned in 11 studies, where it ranged 0-39\% under placebo and 0-70\% under antihistamine. In two studies, this incidence was presented as significantly higher in the antihistamine group (table 4). When an overall effect was computed for all studies, the difference in incidence of sedation between antihistamines and placebo became significant ( $p<0.001$, Mantel-Haenszel test), but the studies were heterogeneous for this variable (consistency across studies: $\mathrm{p}<0.001)$. Besides sedation, several side-effects were mentioned in the studies, especially weight gain, altered taste, headache and dry mouth. 
Table 2. - Major study characteristics

\begin{tabular}{|c|c|c|c|c|c|c|c|c|c|c|}
\hline \multirow{2}{*}{$\begin{array}{l}{[\text { Ref }]} \\
\text { Year }\end{array}$} & \multicolumn{2}{|c|}{ Medication } & \multirow{2}{*}{$\begin{array}{l}\text { Study } \\
\text { design }\end{array}$} & \multirow{2}{*}{$\begin{array}{c}\text { Evaluable } \\
\text { subjects } \\
n \\
\text { active/ } \\
\text { placebo }\end{array}$} & \multirow{2}{*}{$\begin{array}{c}\text { Age range } \\
\text { yrs }\end{array}$} & \multirow{2}{*}{$\begin{array}{c}\text { Males/ } \\
\text { females }\end{array}$} & \multirow{2}{*}{$\begin{array}{l}\text { Asthma } \\
\text { severity }\end{array}$} & \multirow{2}{*}{$\begin{array}{l}\text { Asthma } \\
\text { definition }\end{array}$} & \multirow{2}{*}{$\begin{array}{l}\text { Study } \\
\text { duration } \\
\text { weeks }\end{array}$} & \multirow{2}{*}{$\begin{array}{l}\text { Asthma } \\
\text { co-therapy }\end{array}$} \\
\hline & Drug & $\begin{array}{l}\text { Dose } \\
\mathrm{mg}\end{array}$ & & & & & & & & \\
\hline $\begin{array}{l}{[26]} \\
1980\end{array}$ & Ketotifen & 4 & $\mathrm{CO}$ & $38 / 38$ & $16-66$ & $34 / 16$ & $\begin{array}{l}\text { Mild \& } \\
\text { moderate }^{+}\end{array}$ & $\begin{array}{l}\text { FEV } 1>40 \% \\
\operatorname{Rev}>20 \%\end{array}$ & $4 / 4$ & IBA, DSCG, ICS \\
\hline $\begin{array}{l}{[27]} \\
1980\end{array}$ & Ketotifen & 2 & PG & $43 / 38$ & $26-74$ & $36 / 50$ & Severe $^{+}$ & $\operatorname{Rev}>15 \%$ & 3 & $\begin{array}{l}\text { IBA, DSCG, ICS, OCS } \\
\text { (OCS-sparing study) }\end{array}$ \\
\hline $\begin{array}{l}{[28]} \\
1981\end{array}$ & Ketotifen & 2 & $\mathrm{CO}$ & $31 / 31$ & $7-55$ & $17 / 14$ & Mild* & $\begin{array}{l}\text { FEV } 1>70 \% \\
\text { Var }>20 \%\end{array}$ & $4 / 4$ & IBA, DSCG, ICS \\
\hline $\begin{array}{l}{[29]} \\
1981\end{array}$ & Oxatomide & 180 & PG & $30 / 32$ & $\geq 16$ & ND & $\begin{array}{l}\text { Moderate } \\
\& \text { severe }^{+}\end{array}$ & $\operatorname{Rev}>20 \%$ & 28 & IBA, DSCG, ICS \\
\hline $\begin{array}{l}{[30]} \\
1981\end{array}$ & Ketotifen & 2 & PG & $24 / 21$ & $20-51$ & $26 / 36$ & Mild* & $\begin{array}{l}\text { Near normal } \\
\text { lung function }\end{array}$ & 12 & IBA, OX \\
\hline $\begin{array}{l}{[31]} \\
1986\end{array}$ & Ketotifen & 2 & PG & $15 / 12$ & $12-60$ & ND & $\begin{array}{l}\text { Mild \& } \\
\text { moderate }^{+}\end{array}$ & $\begin{array}{l}\text { Rev }>20 \% \\
\text { Pollen asthma }\end{array}$ & 20 & IBA, ICS, OCS \\
\hline $\begin{array}{l}{[32]} \\
1987\end{array}$ & Terfenadine & 240 & $\mathrm{CO}$ & $46 / 46$ & $12-53$ & $26 / 26$ & Mild* & $\begin{array}{l}\text { FEV } 1>70 \% \\
\text { ATS criteria } \\
(1962)\end{array}$ & $2 / 2$ & IBA, OX, DSCG \\
\hline $\begin{array}{l}{[33]} \\
1988\end{array}$ & Azelastine & 8.8 & PG & $11 / 10$ & $18-45$ & $19 / 5$ & Mild $^{+}$ & $\operatorname{Rev}>15 \%$ & 7 & IBA \\
\hline $\begin{array}{l}{[34]} \\
1989\end{array}$ & Ketotifen & 2 & PG & $118 / 111$ & $6-51$ & $121 / 124$ & Mild* & $\operatorname{Rev}>20 \%$ & 12 & IBA, OX \\
\hline $\begin{array}{l}{[35]} \\
1989\end{array}$ & Picumast & 2 & PG & $56 / 51$ & $21-60$ & $62 / 45$ & $\begin{array}{l}\text { Mild \& } \\
\text { moderate }^{+}\end{array}$ & $\begin{array}{l}\mathrm{FEV}_{1} / \mathrm{VC} 50-68 \\
\operatorname{Rev}>15 \%\end{array}$ & 8 & IBA, IAC, OX, ICS \\
\hline $\begin{array}{l}{[36]} \\
1990\end{array}$ & Terfenadine & 540 & $\mathrm{CO}$ & $17 / 17$ & $22-45$ & $8 / 10$ & Mild* & Pollen asthma & $4 / 4$ & IBA \\
\hline $\begin{array}{l}{[37]} \\
1990\end{array}$ & Azelastine & 8 & PG & $50 / 49$ & $12-61$ & $72 / 27$ & $\begin{array}{l}\text { Moderate } \\
\& \text { severe* }\end{array}$ & $\begin{array}{l}\text { FEV } 140-80 \% \\
\operatorname{Rev}>15 \%\end{array}$ & 12 & IBA, OX \\
\hline $\begin{array}{l}{[19]} \\
1992\end{array}$ & Pemirolast & 100 & $\mathrm{CO}$ & $34 / 31$ & $14-64$ & ND & Mild* & $\begin{array}{l}\text { FEV } 1>65 \\
\operatorname{Rev}>15 \%\end{array}$ & 6 & IBA \\
\hline $\begin{array}{l}{[20]} \\
1995\end{array}$ & Loratadine & 20 & $\mathrm{CO}$ & $32 / 32$ & $18-70$ & $15 / 20$ & $\begin{array}{l}\text { Moderate } \\
\& \text { severe* }\end{array}$ & $\begin{array}{l}\text { Methachol test } \\
\text { Rev }>15 \%\end{array}$ & 4 & $\begin{array}{l}\text { IBA, IAC, OBA, OX, } \\
\text { DSCG, ICS, OCS }\end{array}$ \\
\hline $\begin{array}{l}{[21]} \\
1995\end{array}$ & Cetirizine & 10 & PG & $84 / 69$ & $12-70$ & $82 / 104$ & $\begin{array}{l}\text { Mild \& } \\
\text { moderate* }\end{array}$ & $\begin{array}{l}\text { FEV } 150-80 \% \\
\text { Rev }>15 \% \\
\text { Pollen asthma }\end{array}$ & 6 & IBA, IAC, OBA, OX \\
\hline $\begin{array}{l}{[22]} \\
1995\end{array}$ & Terfenadine & 240 & $\mathrm{CO}$ & $42 / 42$ & $25-60$ & $21 / 28$ & Severe* & $\begin{array}{l}\text { Rev }>15 \% \\
\text { Poorly controllec } \\
\text { asthma }\end{array}$ & ed $^{4}$ & $\begin{array}{l}\text { IBA, IAC, OBA, OX, } \\
\text { DSCG, ICS, OCS }\end{array}$ \\
\hline $\begin{array}{l}{[23]} \\
1996\end{array}$ & Azelastine & 12 & PG & $90 / 50$ & $12-73$ & $124 / 69$ & $\begin{array}{l}\text { Moderate } \\
\& \text { severe }^{+}\end{array}$ & $\begin{array}{l}\text { FEV } 130-80 \% \\
\text { Rev }>15 \%\end{array}$ & 28 & $\begin{array}{l}\text { IBA, IAC, OBA, OX, } \\
\text { DSCG, ICS } \\
\text { (ICS-sparing study) }\end{array}$ \\
\hline $\begin{array}{l}{[24]} \\
1996\end{array}$ & Cetirizine & 20 & PG & $10 / 8$ & $13-59$ & $15 / 13$ & $\begin{array}{l}\text { Mild \& } \\
\text { moderate* }\end{array}$ & $\begin{array}{l}\text { FEV } 1>50 \% \\
\operatorname{Rev}>15 \%\end{array}$ & 26 & IBA, IAC, OBA, OX \\
\hline $\begin{array}{l}{[25]} \\
1996\end{array}$ & Azelastine & 8 & PG & $105 / 116$ & $12-74$ & $99 / 133$ & $\begin{array}{l}\text { Mild \& } \\
\text { moderate }^{+}\end{array}$ & $\begin{array}{l}\text { FEV } 140-75 \% \\
\operatorname{Rev}>15 \%\end{array}$ & 16 & IBA, OX \\
\hline
\end{tabular}

CO: crossover; PG: parallel groups; FEV1: forced expiratory volume in one second (expressed as percentage predicted); Rev: reversibility; ATS: American Thoracic Society; FEV1/VC: FEV1/vital capacity; IBA: inhaled $\beta$-agonist; DSCG: disodium chromoglycate; ICS: inhaled corticosteroid; OCS: oral corticosteroid; OX: oral xanthines; IAC: inhaled anticholinergic; ND: not defined. *: according to authors; +: from data. 


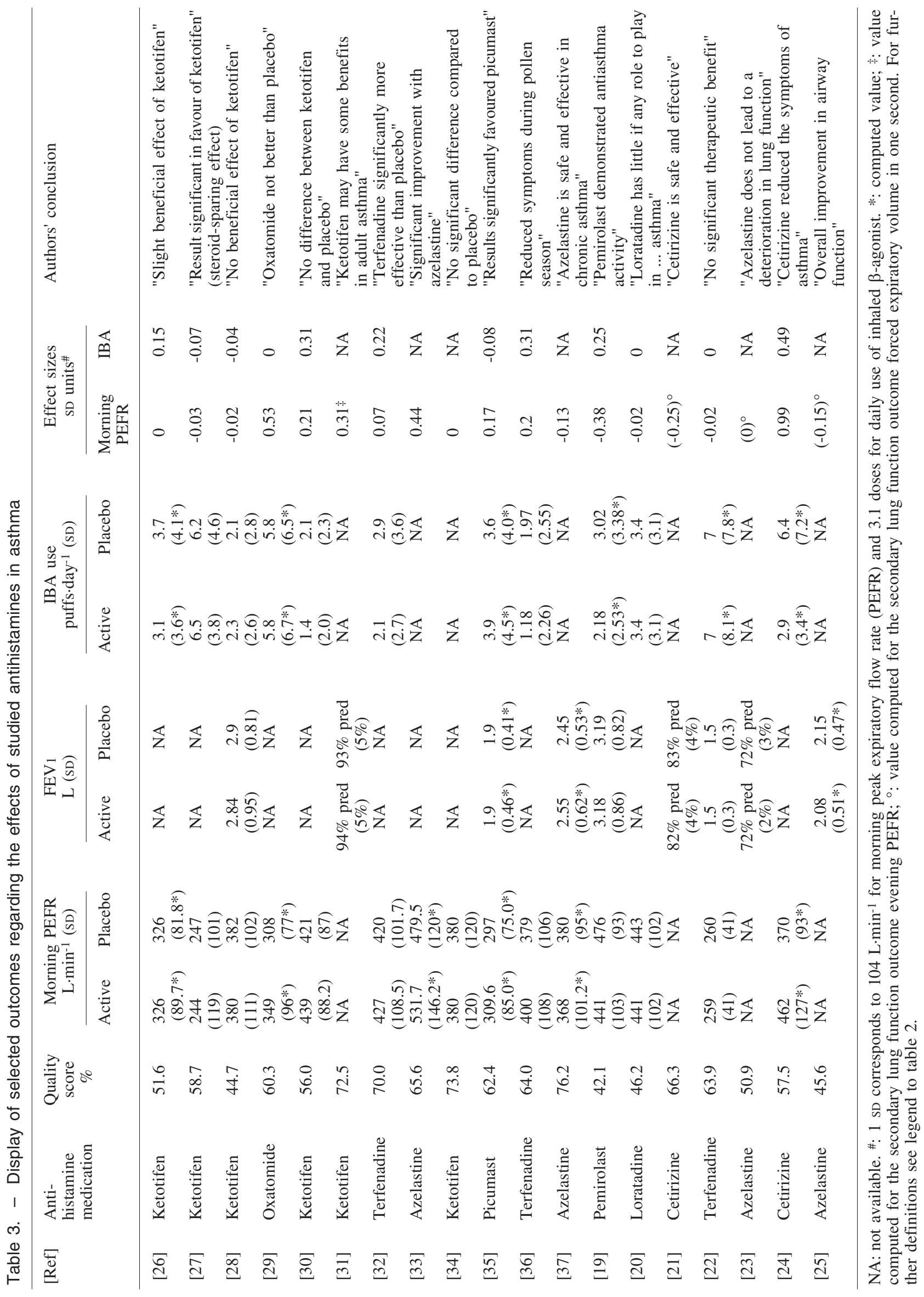




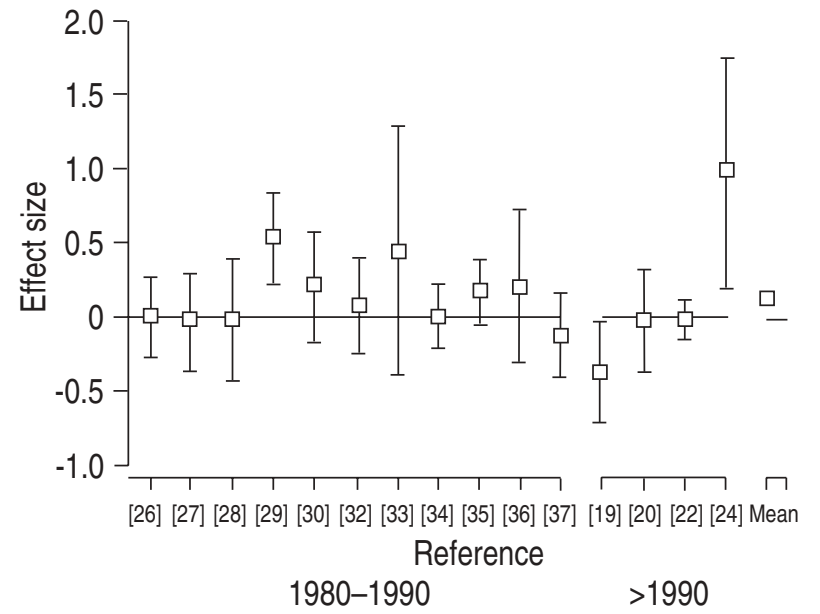

Fig. 1. - Effect sizes for morning peak expiratory flow rate: individual studies, and mean effect size. Bars indicate the $95 \%$ confidence interval. Positive values favour the antihistamine, negative values the placebo. Drugs used were as follows: ketotifen [26-28, 30, 34]; oxatomide [29]; terfenadine [22, 32, 36]; azelastine [33, 37]; picumast [35]; permirolast [19]; loratidine [20]; cetirizine [24].

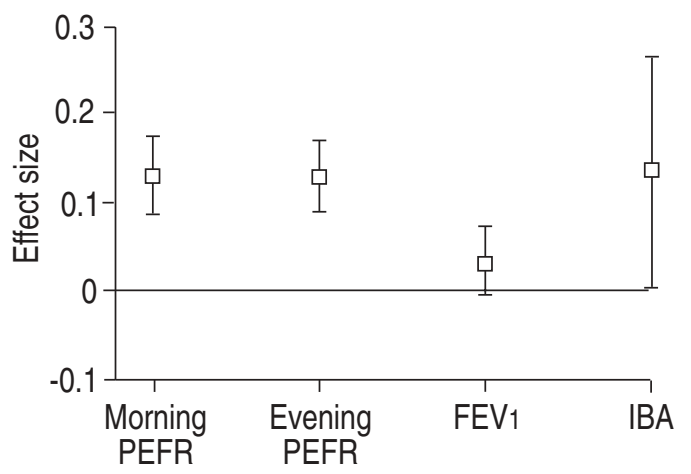

Fig. 2. - Mean effect sizes for lung function variables and daily use of inhaled bronchodilators. Values are mean effect sizes for: morning peak expiratory flow (PEFR; 15 trials); evening PEFR (14 trials); forced expiratory volume in one second (FEV1; 10 trials); and inhaled $\beta$-agonists (IBA; 12 trials). Bars indicate the $95 \%$ confidence interval.

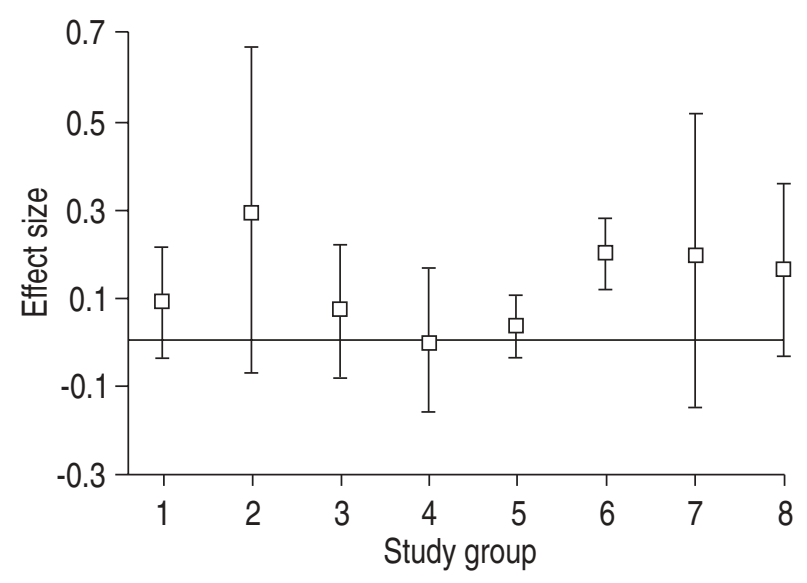

Fig. 3. - Sensitivity analyses on mean effect sizes (morning peak expiratory flow rate). Values are mean size effects for groups of studies as follows: 1) mild asthma (6 trials); 2) mild-to-moderate asthma (4 trials); 3) moderate-to-severe asthma (5 trials); 4) quality scoring $>70 \%$ (3 trials); 5) all ketotifen studies (5 trials); 6) all studies with "new" antihistamines (10 trials); 7) all studies that excluded oral/inhaled steroids (8 trials); and 8) all studies except steroid-sparing trials (14 trials). Bars indicate the $95 \%$ confidence interval.
Table 4. - Incidence of sedation and reporting of specific side-effects under antihistamine treatment

\begin{tabular}{|c|c|c|c|}
\hline [Ref.] & $\mathrm{AH}$ & $\begin{array}{l}\text { Incidence } \\
\text { of sedation } \\
\% \text { exposed } \\
\text { patients }\end{array}$ & $\begin{array}{l}\text { Reported } \\
\text { side-effects }\end{array}$ \\
\hline [26] & Ketotifen & $7(15)$ & Drowsiness \\
\hline [29] & Oxatomide & $70(30)$ & Drowsiness, weight gain \\
\hline [30] & Ketotifen & $29(19)$ & Sedation \\
\hline [31] & Ketotifen & $19(0)$ & $\begin{array}{l}\text { Drowsiness, altered taste, } \\
\text { nausea, headache }\end{array}$ \\
\hline [32] & Terfenadine & & Nausea, fatigue \\
\hline [33] & Azelastine & $58 \quad(0)$ & Altered taste \\
\hline [34] & Ketotifen & $-\quad-$ & Sedation \\
\hline [35] & Picumast & $0 \quad(2)$ & Headache \\
\hline [37] & Azelastine & $6 \quad(2)$ & $\begin{array}{l}\text { Drowsiness, altered taste, } \\
\text { dry mouth, headache }\end{array}$ \\
\hline [19] & Pemirolast & $29(39)$ & Headache, fatigue \\
\hline [21] & Cetirizine & $18 \quad(4)$ & $\begin{array}{l}\text { Headache, fatigue, } \\
\text { somnolence, pharyng- } \\
\text { itis, dry mouth }\end{array}$ \\
\hline [23] & Azelastine & $24 \quad(3)$ & $\begin{array}{l}\text { Altered taste, somno- } \\
\text { lence, weight gain, } \\
\text { dry mouth, fatigue, } \\
\text { increased appetite }\end{array}$ \\
\hline [25] & Azelastine & $4 \quad(?)$ & $\begin{array}{l}\text { Altered taste, weight } \\
\text { gain }\end{array}$ \\
\hline
\end{tabular}

Values in parentheses are those of the placebo. Only studies with specific data were included in the reports of sedation.

\section{Discussion}

In a majority of studies, antihistamines induced bronchodilation in comparison to placebo, but this effect was of limited magnitude, with a mean increase of $13 \mathrm{~L}$ in morning PEFR and a 95\% CI of 8-18 L. Similar conclusions apply to the mean effect sizes for evening PEFR and FEV1, with small increases in airway calibres that were statistically significant only for evening PEFR. With antihistamines, some patients decreased their use of inhaled bronchodilators, but this effect was also of limited size, with a mean reduction of 0.4 doses $\cdot$ day $^{-1}$ and a $95 \%$ CI of 0-0.8 doses. Antihistamines were associated with a higher incidence of sedation than placebo, with significant differences between studies and between antihistamines. Antihistamines were also associated with other side-effects, such as weight gain, altered taste, headache and dry mouth. Quality of studies was generally poor, with deficiencies identified in all parts of publications. In addition, definition of asthma and assessment of disease severity were also suboptimal, and a majority of trials included patients with uncontrolled asthma.

Morning PEFR was chosen as the major outcome since it represents a good marker of patient's status, with symptoms commonly related to the degree of bronchoconstriction. An alternative could be a combination of lung function, global symptom score and therapy. Many indices have tried to incorporate these variables, but none is totally convincing and generally accepted, and there is a risk of "false-positive" changes, since all three variables are related, and any change in one of them would be reflected in the others. In addition, it was not possible to combine asthma symptoms scores in a meta-analysis, due to lack of standardization of such scores. By contrast, the use of "rescue" bronchodilators may be more easily compared between studies. This 
would not be the case if the patients studied had wellcontrolled asthma, with minimal use of rescue bronchodilators. Actually, as judged by the overall level of use of symptomatic medications, asthma was seldom controlled at study entry. This has several implications: firstly, it reflects the overall poor quality of asthma therapy, at least according to present guidelines for asthma management; and secondly, the varying degrees of asthma control may confound the pooling of studies, since heterogeneous populations were included with unknown margins for improvement regarding both airway calibre and use of rescue medications. Such margins were nevertheless present in most studies, with the possible exception of steroid-sparing studies or those that included steroid-dependent patients, and a comparison of airway calibre and use of inhaled bronchodilators which may provide valuable insight in the effect of preventive medication. In theory, such medications are indeed intended to improve the degree of disease control. In our analysis, combined data show that antihistamines had limited effects on both airway calibre and use of rescue inhalers, suggesting that asthma control was little affected by these medications.

Relatively few studies could be included in this analysis, but the total number of patients included for assessment of the major end point was 582 for the antihistamine group and 557 for the placebo group; this gives some strength to the findings. A common weakness in a majority of published trials was the choice of comparator: few studies were performed with placebo, despite the usefulness of such comparison in early development stages of this indication. In many trials, antihistamines are tested against other antihistamines or inhaled disodium cromoglycate, notwithstanding the practical problems of the latter comparison (use of double dummy techniques) and the prevalence of some doubts regarding the effects of disodium cromoglycate. Since the primary aim of our study was an analysis of efficacy of antihistamines in a new indication, we considered that only studies where antihistamines were compared with placebo could be included. An argument supporting this choice is the high morbidity related to asthma, which would make it unacceptable to encourage the use of these medicines in the absence of clear demonstration of benefits. Even with strong limitations in inclusion, the studies retrieved were not of the highest quality, with a mean quality score of $59 \%$. All studies were, nevertheless, included in the main analysis, and a separate analysis of the three studies with higher quality scores did not modify the overall conclusions, since it resulted in almost identical scores for antihistamines and placebo. Improvement is certainly needed in the design and analysis of trials performed with antihistamines in asthma [11]. Improvement is also needed in the definition of asthma used as the inclusion criterion: only two studies mentioned valid criteria, either the American Thoracic Society definition, or the results of a methacholine test, in addition to typical symptoms. Confusion was also possible regarding the degree of severity of asthma, which was usually assessed according to physiological criteria, instead of therapy needed to control asthma. This affected variance and interpretation of the data.

We considered in this analysis all antihistamines as a single class for their asthma effects, and a pooling was made of the results obtained with eight separate antihistamines (picumast, oxatomide, ketotifen, azelastine, terfenadine, pemirolast, loratadine and cetirizine). Of the 19 studies included, six concerned ketotifen, and new antihistamines were investigated in 13 studies. We believe the decision to pool all studies was acceptable since the common property of all medications was the one leading to their claimed efficacy, a potent and specific histamine $\mathrm{H}_{1}$-receptor blocking effect. Our choice is supported by the testing of homogeneity of studies, that rejects heterogeneity for the measurements of morning PEFR and the use of rescue bronchodilators. A separate analysis was, nevertheless, conducted for the group of studies with new antihistamines: it did not affect the overall findings, especially after discarding the data from a small study [24]. That study was, however, used in the analysis, since we decided to include data from all recent studies; it also illustrated the efforts of this medication's manufacturers to investigate their product in asthma [9]. Additional properties have been suggested for several drugs tested, but convincing evidence of the clinical relevance of such effects in asthma is still lacking. No evidence was present that significant differences exist between the eight antihistamines tested with regard to effects in asthma. A recent study investigating the action of seven compounds in allergen-induced skin and lung reactions has reported that all medications tested had small bronchodilator effects, ranging 3-9\%, in parallel to their protective effects against histamine-induced skin wheals [38]. This is in agreement with our study, where most antihistamines had limited bronchodilator effects.

The analysis included only studies published after January 1980. This date coincides with the launch of the first antihistamine in asthma, ketotifen, and several new antihistamines have been developed and tested in asthma since then. As mentioned, antihistamines are commonly used by asthma patients. We believe that the evidence collected over a $15 \mathrm{yr}$ period, at a time of well-defined methodology for clinical trials, makes a reassessment possible, and that data produced in that period apply to the present day. Analysis was also restricted to articles published in English. This choice is justified by the fact that all stages of major studies are performed in that language, including publication. An overview of published articles, reviews or books is reassuring in this regard, confirming that no result from a major trial has been published in another language. Another choice was to restrict inclusions to doubleblind randomized trials. We believe this was justified by the need for strong evidence in favour or against the use of antihistamines in asthma, as already mentioned. Peer-review process was another criterion for including studies. It is often an indication of better design, since a study performed for publication purposes usually fulfills minimal quality requirements. In this analysis, we took indications of dates of submission and acceptance as evidence that a peer-review process had occurred, and we considered that articles published in supplements of a journal had not been submitted to the usual peer-review process.

Paediatric studies were not included for several reasons. First, there are arguments in favour of a distinction between childhood and adult forms of asthma. 
Children and adults may also exhibit very different behaviour regarding key determinants of efficacy, such as compliance with prescribed treatment. Finally, since the values of the morning PEFR were used as the major outcome, it was preferable not to include paediatric studies in the analysis, since measurements of PEFR are less reliable or not available in young children.

Minimal treatment duration was set at 2 weeks for inclusion in the analysis. This is in agreement with the claim that antihistamines need some time to exhibit maximal effects [16]. When several doses of an antihistamine were tested in parallel we included only the data from the most effective dose group: this choice was conservative, since it may only result in over- rather than underestimation of potential effects.

Sensitivity analyses confirm the validity of the conclusions. Separate analyses were performed on subsets of studies, e.g., according to available indices of asthma severity. Results were similar across all degrees of asthma severity: this might be due to misclassification, with most authors assessing severity from lung function rather than from therapy. The sensitivity analysis including studies with the best quality scores showed identical effects for antihistamines and placebo, but included only three trials. Studies performed with new antihistamines tended to show better effects than studies performed with ketotifen, but the difference was small. There was little difference between either the analysis including moderate-to-severe asthma cases (common use of steroids) and the analysis excluding such patients (no use of steroids). Finally, excluding two specific steroid-sparing studies from the analysis did not affect the findings. Due to the small number of relevant studies and the lack of data on airway calibre, it was not possible to restrict the analysis to trials investigating the effects of antihistamines in pollen-induced asthma. This condition may, however, hold some interest for the use of antihistamines. In short, there is at present no argument to support the view that antihistamines would be more effective in a specific type of asthma, or that some antihistamines would be more effective than others to control asthma.

Besides the limited availability of eligible patients, and the overall poor quality of the studies, this analysis has some limitations, such as our method for computing effect sizes. Effect sizes were calculated using the mean measurements made under treatment rather than using a difference between pre- and undertreatment assessments. This is due to the lack of information on the SD values for such differences. However, for those studies where the pretreatment SD was used as an estimate of the SD of the difference, we computed effect sizes with this estimate; this did not affect the results. Nevertheless, most studies included heterogeneous groups of patients, resulting in increased variance of data, with large SD values. This affected the magnitude of effect sizes, decreasing any possible difference between antihistamines and placebo. Our results must then be viewed with some caution for the effect sizes of individual studies or when effect sizes are computed on smaller numbers of studies, as in sensitivity analyses. A publication bias that could affect the conclusions should also be considered. It has been recently suggested that such a publication bias exists, but it would be due to so-called negative studies, where the antihistamine does not demonstrate effects in asthma [11]. In addition, it is unlikely that major studies have reached conclusions supporting the use of antihistamines in asthma, without being published. Both points tend to support the validity of the present analysis.

Investigations on the effects of antihistamines in asthma have started since the beginning of the 1980s, encouraged by the publicized effects of ketotifen in this indication, but few positive results have been obtained. There could be several reasons for this. Asthma is a heterogeneous disease, and it is difficult to identify large numbers of cases of comparable severity, especially if inclusion of uncontrolled asthma is accepted [39]. As a consequence, many investigators tend to recruit small series of patients, and the validity of such studies is, therefore, limited. In addition, the mode of action of ketotifen has been questioned, and the theoretical evidence supporting the role of antihistamines in asthma is getting thinner, in parallel to improved understanding of the pathophysiology of asthma. Nevertheless, many asthma patients are still regularly treated with oral antihistamines for respiratory purposes, despite confusing data. This use should actually rely on convincing evidence, since recent data suggest that antihistamines are not always safe compounds, especially for prolonged or repeated use [40, 41]. Another argument for assessing all available evidence for a potential use of antihistamine is the rapid development of inhaled corticosteroids as the cornerstone for asthma therapy. Despite previous concerns, there are now good arguments to consider this medication safe and effective, at the doses recommended [2]. In this background, the place of any treatment that would present itself as an alternative to optimally used corticosteroids must be carefully weighted [25]. If efficacy of antihistamines in asthma is at best limited, as suggested by the present analysis, their use in this indication could carry the risk of discouraging patients or prescribers from using treatments that have provided evidence of benefits; it could also induce misplaced feelings of security.

We believe that the methodology used in this analysis has resulted in valid data, contributing to the necessary reassessment of the role of antihistamines in asthma. Trials performed with antihistamines in asthma have usually resulted in questionable conclusions, partly due to the small numbers of cases included, and also due to suboptimal quality of most studies. Present data combining information on two outcomes, airway calibres and use of rescue bronchodilators, collected on nearly 600 asthma patients exposed to antihistamines, should also be interpreted as an incentive for improving design, analysis and presentation of asthma intervention studies, especially with preventive medications. For instance, as recently recalled, studies should include only patients with controlled asthma, preferably of similar severity [39].

In conclusion, this meta-analysis has shown that antihistamines and placebo differ little in their effects on asthma control. Tested antihistamines perform equally in that respect with a small bronchodilator effect or a small reduction in the use of rescue inhalers. However, the limited amplitude of these effects does not provide evidence that antihistamines improve asthma control, 
but the validity of our assessment is limited by the overall poor quality of investigations. A final appraisal of the role of antihistamines in asthma must await studies of better design and standardized therapeutic outcomes, e.g., including patients with controlled asthma. Antihistamines have side-effects, and the risk-benefit ratio of these agents must be determined before accepting them for prolonged use in asthma.

Acknowledgement: The help of M. Cucherat is gratefully acknowledged for the statistical section.

\section{References}

1. International Consensus Report on Diagnosis and Management of Asthma. Allergy (Suppl.) 1992; 47: 1-61.

2. Barnes PJ. Inhaled glucocorticoids for asthma. $N \mathrm{Engl}$ J Med 1995; 332: 868-875.

3. Auty RM. Problems with the identification of new antiallergic drugs. Pharmakotherapie 1981; 6: 268-274.

4. Grant SM, Goa KL, Fitton A, Sorkin EM. Ketotifen. A review of its pharmacodynamic and pharmacokinetic properties, and therapeutic use in asthma and allergic disorders. Drugs 1990; 40: 412-448.

5. Kurosawa M. Prophylactic antiasthma drugs in Japan. J Asthma 1990; 27: 299-306.

6. Howarth PH. Histamine and asthma: an appraisal based on specific $\mathrm{H}_{1}$-receptor antagonism. Clin Exp Allergy 1990; 20 (Suppl. 2): 31-41.

7. EAACI Position Paper. The clinical safety of $\mathrm{H}_{1}$-receptor antagonists. Allergy 1996; 51: 666-675.

8. Rafferty P. Antihistamines in the treatment of clinical asthma. J Allergy Clin Immunol 1990; 88: 647-650.

9. Bernheim J, Arendt C, de Vos C. Cetirizine: more than an antihistamine? Agents Actions (Suppl.) 1991; 34: 269293.

10. Simons FER, Simons KJ. The pharmacology and use of $\mathrm{H}_{1}$-receptor antagonist drugs. N Engl J Med 1994; 330: 1663-1670.

11. Bousquet J, Godard P, Michel FB. Antihistamines in the treatment of asthma. Eur Respir J 1992; 5: 1137-1142.

12. Holgate ST. Antihistamines in the treatment of asthma. Clin Rev Allergy 1994; 12: 65-78.

13. Sacks HS, Berrier J, Reitman D, Ancona-Berk VA, Chalmers TC. Meta-analysis of randomized controlled trials. N Engl J Med 1987; 316: 450-455.

14. L'Abbé KA, Detsky AS, O'Rourke K. Meta-analysis in clinical research. Ann Intern Med 1987; 107: 224-233.

15. Berlin JA, Laird NM, Sacks HS, Chalmers TC. A comparison of statistical methods for combining event rates from clinical trials. Stat Med 1989; 8: 141-151.

16. Gibaldi M. Meta-analysis. A review of its place in therapeutic decision making. Drugs 1993; 46: 805-818.

17. Chalmers TC, Smith H, Blackburn B, et al. A method for assessing the quality of a randomized control trial. Controlled Clin Trials 1981; 2: 31-49.

18. Kirkwood BR. Essentials of Medical Statistics. Blackwell Scientific Publications, Oxford, 1988.

19. Kemp JP, Bernstein IL, Bierman CW, et al. Pemirolast, a new oral nonbronchodilator drug for chronic asthma. Ann Allergy 1992; 68: 488-491.

20. Ekström T, Osterman K, Zetterström O. Lack of effect of loratadine on moderate to severe asthma. Ann Allergy 1995; 75: 287-289.

21. Grant JA, Nicodemus CF, Findlay SR, et al. Cetirizine in patients with seasonal rhinitis and concomitant asthma: prospective, randomized, placebo-controlled trial. $J$ Allergy Clin Immunol 1995; 95: 923-932.

22. Wood-Baker R, Smith R, Holgate ST. A double-blind, placebo controlled study of the effect of the specific his- tamine $\mathrm{H}_{1}$-receptor antagonist, terfenadine, in chronic severe asthma. Br J Clin Pharmac 1995; 39: 671-675.

23. Busse WW, Middleton E, Storms W, et al. Corticosteroid-sparing effect of azelastine in the management of bronchial asthma. Am J Respir Crit Care Med 1996; 153: 122-127.

24. Aaronson DW. Evaluation of cetirizine in patients with allergic rhinitis and perennial asthma. Ann Allergy 1996; 76: 440-446.

25. Azelastine-Asthma Study Group -AASG-. An evaluation of the efficacy and safety of azelastine in patients with chronic asthma. J Allergy Clin Immunol 1996; 97: 1218-1224.

26. Dyson AJ, Mackay AD. Ketotifen in adult asthma. BMJ 1980: 360-361.

27. Lane DJ. A steroid-sparing effect of ketotifen in steroiddependent asthmatics. Clin Allergy 1980; 10: 519-525.

28. Petheram IS, Moxham J, Bierman CW, McAllen M, Spiro SG. Ketotifen in atopic asthma and exerciseinduced asthma. Thorax 1981, 36: 308-312.

29. Brompton Hospital/MRC Collaborative Trial. A controlled trial of oxatomide in the treatment of asthma with or without perennial rhinitis. Clin Allergy 1981; 11: 483-490.

30. Mattson K, Poppius H, Ahonen A, et al. Comparison of ketotifen, disodium cromoglycate and placebo in the treatment of adult patients with mild extrinsic asthma. Clin Allergy 1981; 11: 237-242.

31. Tinkelman DG, Webb CS, Vanderpool GE, Carroll MS, Spangler DL, Lotner GZ. The use of ketotifen in the prophylaxis of seasonal allergic asthma. Ann Allergy 1986; 56: 213-217.

32. Taytard A, Beaumont D, Pujet JC, Sapene M, Lewis PJ. Treatment of bronchial asthma with terfenadine; a randomized controlled trial. Br J Clin Pharmac 1987; 24 : 743-746.

33. Gould CAL, Ollier S, Aurich R, Davies RJ. A study of azelastine in patients with extrinsic asthma, and its effect on airway responsiveness. Br J Clin Pharmac 1988; 26 : $515-525$.

34. Medici TC, Radielovic P, Morley J. Ketotifen in the prophylaxis of extrinsic bronchial asthma. A multicenter controlled double-blind study with a modified-release formulation. Chest 1989; 96: 1252-1257.

35. Boerner D, Metz K, Eberhardt R. Efficacy and tolerability of picumast dihydrochloride in comparison with placebo in asthma patients. Arznheim-Forsch 1989; 39: 1363-1367.

36. Rafferty P, Jackson L, Smith R, Holgate ST. Terfenadine, a potent histamine $\mathrm{H}_{1}$-receptor antagonist in the treatment of grass pollen sensitive asthma. Br J Clin Pharmac 1990; 30: 229-235.

37. Tinkelman DG, Bucholtz GA, Kemp JP, et al. Evaluation of the safety and efficacy of multiple doses of azelastine in adult patients with bronchial asthma overtime. Am Rev Respir Dis 1990; 141: 569-574.

38. Wood-Baker R, Holgate ST. The comparative actions and adverse effect profile of single doses of $\mathrm{H}_{1}$-receptor antihistamines in the airways and skin of subjects with asthma. J Allergy Clin Immunol 1993; 91: 1005-1014.

39. Cockroft DW, Swystun VA. Asthma control versus asthma severity. J Allergy Clin Immunol 1996; 98: 10161018.

40. Monahan BP, Ferguson CL, Killeavy ES, Lloyd BK, Troy J, Cantilena LR. Torsades de pointe occurring in association with terfenadine use. JAMA 1990; 264: 2788-2790.

41. Clarke A, Love H. Astemizole-induced ventricular arrhythmias: an unexpected cause of convulsions. Int $J$ Card 1991; 33: 94-97. 